A N N A L E S Annales de Bretagne et des Pays de l'Ouest

Anjou. Maine. Poitou-Charente. Touraine

$121-1 \mid 2014$

Varia

\title{
La Paroisse, communauté et territoire
}

Marie-Madeleine de Cevins

\section{(2) OpenEdition}

Journals

Édition électronique

URL : http://journals.openedition.org/abpo/2743

DOI : $10.4000 / a b p o .2743$

ISBN : 978-2-7535-3407-0

ISSN : 2108-6443

Éditeur

Presses universitaires de Rennes

Édition imprimée

Date de publication : 27 mars 2014

Pagination : 193-194

ISBN : 978-2-7535-3405-6

ISSN : 0399-0826

Référence électronique

Marie-Madeleine de Cevins, "La Paroisse, communauté et territoire », Annales de Bretagne et des Pays de l'Ouest [En ligne], 121-1 | 2014, mis en ligne le 27 mars 2014, consulté le 23 septembre 2020. URL: http://journals.openedition.org/abpo/2743 ; DOI : https://doi.org/10.4000/abpo.2743 


\section{Comptes rendus}

Merdrignac, Bernard, Pichot, Daniel, Plouchart, Louisa, Provost, Georges (dir.), La Paroisse, communauté et territoire. Constitution et recomposition du maillage paroissial, Rennes, PUR, coll. « Histoire », 2013, 541 p.

Quiconque s'occupe d'histoire, de géographie ou de sociologie religieuse affronte un jour ou l'autre le point nodal du cadre paroissial. D'innombrables travaux lui ont été consacrés. Ce livre ne ressemble pourtant à aucun de ses prédécesseurs.

Il réunit les communications présentées pendant quatre ans (2008-2011) au cours de journées d'étude organisées à l'Université de Rennes à l'initiative de Bernard Merdrignac, ainsi que plusieurs articles portant sur le même thème - soit un total de vingt contributions. Il procède d'une démarche pour le moins inhabituelle : elle vise à comprendre le passé à l'aide de la situation présente, plutôt que l'inverse. En d'autres termes, il s'agit d'appréhender la genèse de la plebs/parrochia au temps où il n'existait pas encore de coïncidence entre communautés chrétiennes et territoire paroissial - celle-ci n'étant entrée dans les mœurs qu'à partir du XIII ${ }^{\mathrm{e}}$ siècle en Occident, avant d'être officialisée par le Concile de Trente -, ceci en observant le fonctionnement des paroisses d'aujourd'hui, déstabilisées par l'effondrement de la pratique catholique et la désertification des campagnes. L'approche est d'autant plus originale qu'elle croise le regard d'historiens, d'archéologues, de géographes, de sociologues et de juristes - portant ainsi la pluridisciplinarité à un niveau maximal. Si la Bretagne est à l'honneur, d'autres régions de l'Occident chrétien sont évoquées, de l'Italie à l'Irlande et à la Bohême.

Dès l'introduction, et à nouveau dans l'épilogue qui sert de conclusion, on comprend ce que l'ouvrage doit à la personnalité hors du commun de son instigateur, Bernard Merdrignac - disparu quelques semaines après la parution du livre. Son immense érudition, sa quête perpétuelle d'outils heuristiques mais aussi sa force de conviction, son engagement personnel - en prise directe avec l'actualité (ecclésiale mais pas seulement...) - et son humour indéfectible insufflent à ce livre l'unité de ton qui, de prime abord, pouvaient lui manquer.

Le film se déroule à l'envers. La première partie dresse (en quatre contributions) le bilan du fonctionnement actuel des paroisses catholiques en France, notamment dans les diocèses bretons. Cartes et analyses détaillées donnent à voir le démantèlement du maillage paroissial qui a suivi l'après-guerre, ruinant ainsi le vieux schéma " un village, un clocher, une paroisse, un curé " (p. 7). Elles révèlent aussi la difficulté des responsables à lui substituer des repères consensuels et fédérateurs dans lesquels desservants et fidèles, pratiquants réguliers ou occasionnels, pourraient se retrouver.

La seconde partie (composée de six contributions) décrit l'institution paroissiale à l'apogée de son adéquation avec un territoire, entre le Concile de Trente et celui de Vatican II. Elle s'intéresse aux normes aussi bien qu'aux pratiques. Deux chapitres particulièrement soignés et convaincants (dus à la plume de Georges Provost) démentent l'idée répandue de paroisses bretonnes qui se seraient conformées en tout point au moule canonique, à propos des paroisses urbaines comme des chapelles de quartier. 
De façon prévisible eu égard aux domaines de prédilection de Bernard Merdrignac, la partie consacrée au Moyen Âge se taille la part du lion (neuf contributions). Et elle s'appuie sur des exemples situés dans le " grand Ouest " continental et insulaire (Armorique, Maine, Normandie, Irlande). On y mesure, à l'aide d'études de cas parfois inédites, à quel point le cadre paroissial était balbutiant, disparate et fluctuant (sur le plan de la densité du réseau des sanctuaires paroissiaux comme sur celui des actes qui s'y déroulaient) au moins jusqu'au XIII ${ }^{\mathrm{e}}$ siècle. Car il n'a pas suffi de fixer les morts (au cimetière) pour fixer les vivants autour d'eux, de désigner les terres soumises à la dîme pour que leurs habitants accomplissent leurs devoirs sacramentels auprès de son destinataire, de hiérarchiser les sanctuaires pour imposer l'usage exclusif ou même prioritaire de l'un d'entre eux à tous les fidèles. Â l'image de l'ecclesia dans son entier, et à l'opposé de la vision qui prévalait dans l'historiographie jusqu'au début des années 1980, la paroisse était une communauté humaine avant que d'être un espace polarisé et délimité par des frontières objectives.

Quelques coquilles, des répétitions (méthodologiques, historiographiques) entre les chapitres et la présence de contributions moins abouties que d'autres n'altèrent en rien la qualité globale et l'intérêt de ce livre. Il est doté en outre de nombreuses cartes et illustrations, souvent en couleur. Une abondante bibliographie ne se limitant pas aux seuls travaux cités par les contributeurs confirme sa dimension d'instrument de travail. Ne manquent, pour la période médiévale et la France de l'Ouest, que les publications de Jean-Michel Matz (sur les paroisses en Anjou) et de Vincent Tabbagh (en Normandie). À l'échelle de l'ensemble de la Chrétienté, on aurait pu mentionner bien d'autres titres (italiens, allemands, hongrois...) cités dans les chapitres VIII et IX ("L'encellulement paroissial ", E. Grélois et L. Delobette) du volume Structures et dynamiques religieuses dans les sociétés de l'Occident latin (1179-1449) dirigé par M.-M. de Cevins et J.-M. Matz (PUR, 2010), ou encore ceux rédigés par l'auteur de ces lignes. Ces lacunes mineures confirment l'inscription de ce volume dans une perspective bretonne.

Marie-Madeleine DE CEVINS

Dufour Anaïs, Le pouvoir des "Dames », femmes et pratiques seigneuriales en Normandie (1580-1620), Rennes, PUR, coll. « Histoire ", 2013, 173 p.

Ce livre est issu d'un mémoire de Master 2 d'histoire moderne soutenu en 2010 à l'université de Rouen et couronné par le prix Mnémosyne qui récompense les travaux de Master portant sur l'histoire des femmes et du genre. Dans cet ouvrage publié en 2013, Anaïs Dufour explore le pouvoir des " Dames " de 1580 à 1620 en reconstruisant le parcours de femmes majoritairement nobles qui - à la faveur d'un héritage ou de circonstances particulières - prennent possession d'une seigneurie.

Pour cela, elle a mené ses recherches en Normandie, une province marquée par une forte densité nobiliaire et une coutume sévère pour les femmes, principalement aux Archives départementales de Seine-Maritime dans le fonds du bailliage de Rouen. Son travail s'appuie sur les rôles dressés lors des convocations de l'arrièreban normand, régulièrement mobilisé pendant les Guerres de religion, et déjà utilisés dans leurs travaux sur la noblesse par Jean-Marie Constant et Michel Nassiet. Elle a également analysé les articles de la coutume de Normandie rédigée officiellement en 1583 et leurs commentaires par les juristes normands ainsi que les règlements 